\title{
Violência doméstica como tema de estudo em programas de pós-graduação no estado do Rio de Janeiro
}

\author{
Sueli Bulhões da Silva \\ Pontifícia Universidade Católica (PUC-Rio)
}

\author{
Antonio Carlos de Oliveira \\ Pontifícia Universidade Católica (PUC-Rio)
}

Violência doméstica como tema de estudo em programas de pós-graduação no estado do Rio de Janeiro

Resumo: Este artigo discute os resultados de uma pesquisa que objetivou mapear a produção discente (dissertações e teses) no âmbito da violência doméstica, entre 1990 e 2006, em programas de pós-graduação em Serviço Social, Psicologia e Saúde Pública de instituições localizadas no estado do Rio de Janeiro. O estudo, centrado na análise de tendências, avanços e lacunas da referida produção, revelou a prevalência de pesquisas voltadas para o segmento infanto-juvenil, a mudança de foco da caracterização do fenômeno para a discussão de sua dinâmica, e o reduzido número de trabalhos sobre idosos.

Palavras-chave: violência doméstica, produção discente, programas de pós-graduação no estado do Rio de Janeiro.

\section{Domestic Violence as a Theme of Study in Graduate Programs in Rio de Janeiro State}

Abstract: This article discusses the results of a study that sought to map the production of master's and doctoral students concerning domestic violence, from 1990 to 2006, in graduate programs of Social Work, Psychology and Public Health at institutions located in Rio de Janeiro State. The study focused on the analysis of trends, advances and gaps in this production and revealed a prevalence of studies of children and youth, a change of focus from characterization of the phenomenon to a discussion of its dynamic and a reduced number of studies about the elderly.

Key words: domestic violence, graduate student production, graduate programs in Rio de Janeiro. 


\section{Introdução}

Entendida como uma forma de relação social abusiva, a violência doméstica é um conceito que inclui abusos/maus-tratos cometidos não só contra crianças e adolescentes, mas, também, contra idosos e mulheres em um espaço que deveria ser marcado pelo afeto, parentesco, dependência e confiança, ou seja, o espaço familiar. No Brasil, os estudos da violência doméstica começam a ganhar visibilidade a partir dos anos de 1980, com o movimento de democratização no país, quando se desperta para a defesa e garantia dos direitos de grupos considerados mais vulneráveis, em especial crianças, adolescentes e mulheres. Esta discussão ganha vulto, em primeiro lugar, através dos movimentos femininos e feministas, cujo acúmulo já era, à época, considerável. Uma das conquistas daí decorrentes foi a instalação de equipamentos específicos para atendimento deste segmento, como as Delegacias Especializadas de Atendimento à Mulher (DEAMs) que têm sua primeira unidade implementada em 1985, em São Paulo (UNB, 2008). No rastro deste debate, também se fortalece um movimento nacional voltado para a garantia dos direitos de crianças e adolescentes, que culmina com a inclusão do artigo 227 na nova Constituição da República Federativa do Brasil de 1988, regulamentado no Estatuto da Criança e do Adolescente (ECA), em 1990 (BRASIL, 1995). Posteriormente, com o advento da Política Nacional do Idoso (BRASIL, 2008) e a promulgação do Estatuto do Idoso (BRASIL, 2003), este segmento da população passa a merecer, também, uma atenção diferenciada nas políticas e programas que lhe são dirigidos, principalmente quanto à proteção contra a violência doméstica.

Embora Kowarick (1995, p. 46) afirme que no processo de produção de conhecimento não existe uma relação linear entre as realidades de determinada sociedade e a produção de conhecimento nela existente, ele também considera que possa haver uma influência recíproca. Este momento histórico e os marcos legais que dele emergem, como mediações engendradas na dinâmica da própria sociedade, possibilitam o incremento de referências temáticas, tais como a violência doméstica, transformadas em objeto de investigação. A partir dessa premissa, a pesquisa Mapeamento da produção acadêmica sobre violência doméstica nos programas de pós-graduação, na cidade do Rio de Janeiro, no Período 1990-2006 ${ }^{1}$, cujos resultados são apresentados neste artigo, analisou a produção acadêmica (dissertações de mestrado e teses de doutorado) sobre a violência doméstica nos programas de pós-graduação, especificamente nos de Serviço Social, Psicologia e Saúde Pública, localizados na cidade do Rio de Janeiro, a partir de 1990 (ano da promulgação do ECA) até 2006. Cabe informar que o mapeamento teve como objetivos, identificar:

a) as principais temáticas abordadas;

b) os grupos mais freqüentemente estudados; e

c) os tipos de violência prevalentes na produção em relação a cada grupo.

Vale considerar que, embora não tenha se constituído em um inventário exaustivo da produção na área, a pesquisa permitiu identificar tendências temáticas, avanços e lacunas na produção científica referente à violência que ocorre no espaço intrafamiliar, cuja apresentação e discussão consistem no objetivo do presente artigo.

\section{Método}

O estudo estruturou-se a partir de uma pesquisa documental de cunho exploratório, realizada através do levantamento e da catalogação dos resumos das dissertações e teses, como fontes privilegiadas para análise, que forneceram a base necessária à quantificação e à identificação das tendências, avanços e lacunas na área da violência doméstica, no Rio de Janeiro, no período estudado.

Assim, os procedimentos metodológicos adotados consistiram de:

a) levantamento da produção discente;

b) agrupamento da mesma, a partir de seus recortes temáticos;

c) leitura e análise dos resumos daquelas voltadas para a questão da violência doméstica, buscando identificar as principais temáticas abordadas, os grupos estudados (criança, adolescente, mulher ou idoso) e as abordagens de pesquisa utilizadas;

d) análise e interpretação dos dados obtidos.

As instituições pesquisadas foram: Pontifícia Universidade Católica do Rio de Janeiro (PUC-Rio) Programas de Serviço Social e Psicologia Clínica; 
Universidade Federal do Rio de Janeiro (UFRJ) Programas de Serviço Social e Psicologia; Universidade do Estado do Rio de Janeiro (UERJ) - Programas de Serviço Social, Psicologia Social e Saúde Coletiva; Fundação Oswaldo Cruz (Fiocruz), especificamente a Escola Nacional de Saúde Pública (ENSP) - Programa de Saúde Pública e o Instituto Fernandes Figueira (IFF) - Programa de Saúde da Criança e da Mulher; e Universidade Federal Fluminense (UFF) - Programas de Serviço Social e Psicologia. Este levantamento das produções acadêmicas discentes - realizados nas bibliotecas locais e pela Internet - possibilitou a identificação, no período proposto pela pesquisa, de um total geral de 3.599 trabalhos científicos.

Ao primeiro contato com cada programa, a bolsista do Programa Institucional de Bolsas de Iniciação Científica (Pibic) compareceu munida de uma carta de apresentação destinada aos coordenadores, esclarecendo o teor e os objetivos do estudo, bem como a instituição de origem e o professor responsável pelo referido projeto.

Para o levantamento das dissertações e teses e a obtenção dos resumos das produções voltadas para a questão da violência doméstica, por vezes, foram necessárias mais de uma visita às instituições de ensino, tendo em vista a dificuldade em obter os resumos das produções na biblioteca virtual.

Em uma das instituições, uma greve de funcionários dificultou o contato com os programas, uma vez que seu funcionamento, nesse período, tornou-se esporádico e os horários não eram compatíveis com os anunciados no site da referida universidade.

Uma outra dificuldade na quantificação dos dados e na obtenção dos resumos foi resultante da ausência de catálogos com o acervo das publicações dos programas.

$\mathrm{Na}$ Fiocruz, o ponto de partida foi o Centro Latino-Americano de Estudos de Violência e Saúde (Claves), onde o acervo se constitui de doações de teses e dissertações, defendidas no Brasil e em alguns países da América Latina, mas não de todas as que foram defendidas na Escola Nacional de Saúde Pública e no Instituto Fernandes Figueira. Assim, a alternativa foi a obtenção dos dados de interesse para a realização do mapeamento, através da biblioteca virtual, que se tornou uma ferramenta valiosa.

Cabe ressaltar que, embora as bibliotecas virtuais dos programas tenham se constituído em elemento fundamental para o acesso aos dados, também apresentaram entraves no desenvolvimento da pesquisa. Não foram raros os momentos de dificuldades de acesso - tais como sistema off line - e/ou permanência - queda de rede - na consulta às bibliotecas virtuais, bem como processos de informatização dos dados ainda em construção. Em algumas das bibliotecas consultadas, somou-se o fato de a ordem de catalogação dos autores não seguir critérios claros e/ou possuírem entrada de dados com grande defasagem de data.

A leitura e a análise dos resumos das referidas produções apresentaram desafios devido à qualidade das informações de algumas, bastante incompletas. Mesmo assim, foi possível identificar as principais temáticas de violência doméstica abordadas e os grupos estudados (crianças, adolescente, mulher ou idoso). Quanto ao tipo de pesquisa e à metodologia utilizada, como muitos resumos não forneciam tais informações, procedeu-se ao necessário redimensionamento dos objetivos iniciais, devido à precariedade destes dados.

No total, foram levantadas 3.599 produções acadêmicas, sendo 2.750 dissertações e 849 teses defendidas no período estudado. A coleta de dados foi finalizada em abril de 2007, objetivando uma margem razoável de tempo para o seu lançamento, referente às produções defendidas até julho de 2006.

A etapa seguinte foi o agrupamento das produções a partir do seu recorte temático. Esta etapa possibilitou identificar que, no período de 1990 a julho de 2006, foi produzido um total de 140 teses e dissertações $(4 \%)$ voltadas para a questão da violência, sendo que destas, $71(51 \%)$ tratam da violência no ge$\mathrm{ral}^{2}$ e 69 (49\%), da violência doméstica. Este agrupamento permitiu identificar 48 dissertações e 21 teses que abordavam, especificamente, a temática da violência doméstica.

\section{Resultados}

\section{A temática da violência nas produções dos pro- gramas}

A temática da violência, em maior ou menor grau, está presente em produções de todos os programas pesquisados, conforme pode ser observado na tabela 1.

Aqueles que apresentam produção mais significativa na temática da violência, tanto em geral como doméstica, são da área de saúde. De um total de 11 programas pesquisados, somadas as produções da ENSP, do IFF e do IMS obtém-se um total de 82 trabalhos, o que corresponde a $58,6 \%$ das dissertações e teses.

O Programa de Saúde Pública da ENSP tem sua produção fortemente concentrada em violência no geral: das 43 dissertações e teses encontradas, $70 \%$ tratam desta dimensão do fenômeno. Por outro lado, no IFF, cujo programa está focado na saúde da mulher e da criança, a produção discente na área da violência doméstica mostrou-se bem mais prevalente: $83 \%$ de um total de 18 .

O Programa de Pós-Graduação em Serviço Social da PUC-Rio é o que possui maior número de dissertações (12) na temática de violência doméstica, o que 
Tabela 1 - Distribuição da produção discente sobre violência em geral e violência doméstica nos programas de pós-graduação selecionados, no Rio de Janeiro, no período de 1990 a julho de 2006

\begin{tabular}{lcccccc}
\hline $\begin{array}{l}\text { Abordagens da Violência } \\
\text { Instituições/ Programas }\end{array}$ & \multicolumn{2}{c}{ Violência em geral } & \multicolumn{2}{c}{ Violência Doméstica } & & \\
Dissertações & Teses & Dissertações & Teses & Total & (\%) \\
\hline PUC-Rio/Serviço Social & 02 & $*$ & 12 & $*$ & 14 & $10 \%$ \\
PUC-Rio/Psicologia Clínica & 04 & 02 & 01 & 03 & 10 & $7 \%$ \\
UFRJ/Serviço Social & 03 & 02 & 01 & 0 & 06 & $4 \%$ \\
UFRJ/Psicologia & 07 & 01 & 02 & 02 & 12 & $8 \%$ \\
UFF/Política Social & 02 & $* *$ & 01 & $* *$ & 03 & $2 \%$ \\
UFF/Psicologia & 03 & $* *$ & 01 & $* *$ & 04 & $3 \%$ \\
UERJ/Psicologia Social & 01 & 0 & 0 & 0 & 01 & $1 \%$ \\
UERJ/Saúde Coletiva & 03 & 03 & 11 & 04 & 21 & $15 \%$ \\
UERJ/Serviço Social & 05 & $*$ & 03 & $*$ & 08 & $6 \%$ \\
Fiocruz-ENSP/Saúde Pública & 19 & 11 & 06 & 07 & 43 & $31 \%$ \\
Fiocruz-IFF/Saúde da Criança & 03 & 0 & 10 & 05 & 18 & $13 \%$ \\
e da Mulher & & & & & & \\
TOTAL & $\mathbf{5 2}$ & $\mathbf{1 9}$ & $\mathbf{4 8}$ & $\mathbf{2 1}$ & $\mathbf{1 4 0}$ & $\mathbf{1 0 0 \%}$ \\
\hline
\end{tabular}

Fonte: elaboração dos autores

* Doutorado ainda não teve nenhuma defesa de tese no período compreendido pela pesquisa.

** Programa possui apenas Mestrado.

Tabela 2 - Distribuição da produção discente sobre violência doméstica nos programas de pósgraduação selecionados, no Rio de Janeiro, segundo os grupos estudados e os tipos de violência sofrida, no período de 1990 a julho de 2006

\begin{tabular}{|c|c|c|c|c|c|c|c|c|c|c|c|c|c|c|}
\hline \multirow[b]{3}{*}{ Programas } & \multicolumn{14}{|c|}{ Grupos estudados nas dissertações e teses } \\
\hline & \multicolumn{4}{|c|}{ Mulher } & \multicolumn{5}{|c|}{$\begin{array}{c}\text { Criança e } \\
\text { adolescente }\end{array}$} & \multicolumn{2}{|l|}{ Idoso } & \multicolumn{3}{|c|}{$\begin{array}{l}\text { Mais de } \\
\text { um grupo }\end{array}$} \\
\hline & $\mathbf{S}$ & $\mathbf{F}$ & $\mathbf{P} \quad \mathrm{I}$ & $\mathbf{N} *$ & $\mathbf{S}$ & $\mathbf{F}$ & $\mathbf{P}$ & $\mathbf{N}$ & $*$ & $\begin{array}{llll}\mathbf{S} & \mathbf{F} & \mathbf{P} & \mathbf{N}\end{array}$ & $\mathbf{V} *$ & $\mathbf{S}$ & $\mathbf{F} \mathbf{P} \quad \mathbf{N}$ & * \\
\hline PUC-Rio (1) & & & 2 & 1 & 3 & 1 & & 1 & 3 & & & & & 1 \\
\hline UCc-Rio (2) & & & & & 2 & 1 & & & & & & & & 1 \\
\hline UFRJ (1) & & & & 1 & & & & & & & & & & \\
\hline UFRJ (2) & & & & & 1 & & 1 & & 2 & & & & & \\
\hline UFF (1) & & 1 & & & & & & & & & & & & \\
\hline UFF (2) & & & 1 & & & & & & & & & & & \\
\hline UERJ (1) & & & & & 1 & & & & 2 & & & & & \\
\hline UERJ (2) & & & & & & & & & & & & & & \\
\hline UERJ (3) & & 3 & & 2 & & 1 & & & 6 & & 1 & & & 2 \\
\hline $\operatorname{IFF}(3)$ & 1 & 3 & & 1 & 2 & & 6 & & & & & & & 2 \\
\hline ENSP (3) & 1 & 2 & & 1 & 2 & 1 & 3 & & & & & & & 3 \\
\hline TOTAL & 2 & 9 & 3 & 6 & 11 & 4 & 10 & 1 & 13 & & 1 & & & 9 \\
\hline
\end{tabular}

Fonte: elaboração dos autores

Legenda: $\mathrm{S}=$ Sexual; $\mathrm{F}=$ Física $; \mathrm{P}=$ Psicológica; $\mathrm{N}=$ Negligência $; *=$ Mais de um tipo

(1) Serviço Social; (2) Psicologia; (3) Saúde Coletiva 
pode estar associado ao fato de o referido programa possuir uma linha de pesquisa voltada para o fenômeno da violência nos contextos familiar e institucional.

Também no IMS pode-se atribuir a alta concentração de produções na área de violência doméstica à existência de duas linhas de pesquisa que propiciam o desenvolvimento de estudos na temática, quais sejam "Violências Públicas e Privadas" e "Gênero, Sexualidade e Saúde".

\section{A temática da violência doméstica e os grupos estudados}

Como se pode constatar na tabela 2, o segmento com maior concentração de dissertações e teses é o de crianças e adolescentes, com 39 produções em um total de $69(56,5 \%)$.

Tais resultados fazem eco ao constatado por Assis e Constantino (2003, p. 183):

[...] a década de 90 colocou o tema da Violência contra Crianças e Adolescentes, de forma muito ampla, na pauta da geração de conhecimento científico e de formulação de estratégias sociais. O que foi produzido, freqüentemente fundamentado na lei de proteção que se constituiu com o ECA, avançou na compreensão do fenômeno [...].

Observa-se que as produções voltadas para o estudo da violência doméstica contra mulheres apresentam a segunda maior concentração, com 20 dissertações e teses $(29 \%)$.

Como já dito anteriormente, os movimentos feministas e de mulheres colocaram em pauta, principalmente a partir da década de 1980, no Brasil, a necessidade de reconhecimento dos direitos das mulheres como direitos humanos, conseguindo, inclusive, transformar sua luta em diversas leis. Tal contexto igualmente contribuiu para a ampliação dos estudos acadêmicos sobre os direitos deste grupo, em diversos campos do conhecimento e, em especial, no que se refere à violência doméstica.

Ratificando os dados referentes aos programas da área da saúde, a produção do IFF centrada em relações familiares tem 15 dissertações e teses (83\% do total) tratando da temática da violência doméstica. Destas, cinco referem-se a mulheres, oito a crianças e duas a mais de um grupo.

Considerando-se a produção de todos os programas pesquisados, encontra-se um total de 20 dissertações e teses sobre a violência doméstica contra mulheres e 39 contra crianças e adolescentes. $O$ fato de as produções sobre este último grupo representar quase o dobro em relação aos trabalhos que têm como foco as mulheres também corrobora a constatação de Assis e Constantino (2003).
Quanto aos idosos, há apenas um trabalho. Importante salientar que é, dentre os grupos especialmente vulneráveis abarcados pela pesquisa, o de interesse 'generalizado' mais recente. A esse respeito, Minayo e Souza (2003, p. 233) registram que:

\begin{abstract}
No caso brasileiro, o tema apenas está sendo tocado e problematizado, fato que pode ser atribuído, ao lado de uma falta de prioridade, à novidade do crescimento acelerado de um grupo populacional que, até bem poucas décadas, não era tão significativo. [...] Infelizmente, o estágio inicial em que se encontra o tratamento do tema nos permite apenas dizer que ele passou a fazer parte da pauta dos estudiosos do impacto da violência sobre a saúde, mas apenas na segunda metade da década de 90.
\end{abstract}

Também há que se considerar que o Estatuto do Idoso é uma das mais recentes leis que regulam os direitos e a atenção aos grupos estudados, datando de 2003, tendo posteriormente, apenas, a Lei Maria da Penha, de 2006 (BRASIL, 2007).

Os estudos referentes a mais de um grupo somam nove dissertações e teses, representando $13 \%$ do total de produções sobre violência doméstica. A literatura sobre o tema (FURNISS, 1993; KAMEYAMA, 1998; SOARES, 1999; OLIVEIRA; FERNANDES, 2007) costuma referir a ocorrência concomitante, em uma mesma família de: de mulheres e sua prole tanto sendo vitimadas pelo mesmo perpetrador como também autoras de violência contra seus filhos. Também há, com freqüência, a leitura de que ao assistirem à violência praticada contra suas mães, crianças e adolescentes sofrem impactos que podem ser considerados como violência psicológica.

\section{Os grupos estudados e os tipos de violência}

O mapeamento permitiu observar que, com relação à violência doméstica praticada contra mulheres, há maior concentração de estudos em violência física (45\%), seguida de mais de um tipo (30\%). Uma possibilidade, quanto à explicação desta prevalência, reside no fato de os homicídios de mulheres por seus parceiros ter sido objeto de inúmeras discussões pautadas pelos movimentos feministas e de mulheres, no Brasil. Outro aspecto a ser considerado é que, em nosso país, historicamente, a violência física figurou como justificável, tendendo à naturalização, o que, em parte, pode explicar a necessidade de desenvolvimento de pesquisas que busquem dar fundamentos à desconstrução destes argumentos.

No que diz respeito a crianças e adolescentes, as produções estão distribuídas quase que igualmente entre mais de um tipo (33\%), violência sexual (28\%) e violência psicológica $(26 \%)$. Neste seg- 
mento etário, chama a atenção a alta prevalência de estudos sobre violência psicológica, dada sua pouca freqüência na literatura brasileira, apesar de descrita pelos estudiosos como extremamente insidiosa e estando na base de outros tipos de violência (GUERRA, 1985, AZEVEDO; GUERRA, 1989, OLIVEIRA; FERNANDES, 2007). Por outro lado, é surpreendente o baixo índice de estudos em violência física (10\%), em função da maior evidência de seus sinais - favorecendo sua identificação - e, mais ainda, que no caso das mulheres, a naturalização de seu emprego como recurso 'pedagógico' para educação de crianças e adolescentes. Na categoria mais de um tipo, embora a qualidade dos resumos reduzam com precisão as informações acerca de que violências figuram em cada caso, vale registrar o quanto a literatura sobre o tema freqüentemente relaciona a ocorrência concomitante de abusos físicos ou sexuais e psicológicos, tomando emprestado da área da saúde o termo co-morbidade para descrever tal fenômeno. $\mathrm{O}$ expressivo percentual relativo à violência sexual deve ser compreendido, dentre outros aspectos, em um contexto no qual a temática ganha grande visibilidade na pauta mundial com a discussão acerca do tráfico de crianças para fins sexuais e das redes de pedofilia na Internet (ONU, 2006).

Merece registro o fato de ter sido identificado apenas um estudo abordando a negligência em relação a crianças e adolescentes. O estágio atual de sua compreensão se expressa em leis que a classificam como um tipo de violência doméstica para todos os grupos estudados, e em definições cada vez mais precisas, como se pode observar a seguir:

A negligência ocorre quando os pais ou responsáveis deixam de prover - dispondo de condições para tal - os meios, recursos e cuidados necessários ao pleno e sadio desenvolvimento físico e mental da criança ou adolescente sob sua guarda e/ou responsabilidade(OLIVEIRA; FERNANDES, 2007,p. 138).

Apesar disto, persiste grande polêmica envolvendo sua identificação. Isso se deve, em parte, ao fato de os profissionais voltados para seu atendimento terem dificuldades em discernir entre atitudes efetivamente negligentes de miséria - ausência ou precariedade de recursos para suprir necessidades - ou falta de conhecimentos adequados - por exemplo, níveis de competência ou autonomia para execução de algumas tarefas - por parte dos cuidadores.

Quanto aos idosos, cabe reiterar que, nos programas estudados, este segmento tem atenção ainda incipiente, tendo sido encontrado apenas um estudo tratando de mais de um tipo de violência.

Finalmente, quando se analisa os estudos referentes a mais de um grupo, constata-se que estão todos associados a mais de um tipo de violência, totalizando nove dissertações e teses, o que equivale a $13 \%$ do total da produção em violência doméstica. Tal constatação ratifica o argumento desenvolvido acima no que se refere à co-morbidade, fenômeno que tende a se mostrar acentuado ao se estudar a violência contra crianças, adolescentes, mulheres e idosos conjuntamente.

\section{Discussão}

Cientes de que os programas de pós-graduação estrito-senso constituem o locus privilegiado de produção de conhecimento, onde docentes e discentes desenvolvem projetos voltados para temáticas de relevância social, para os objetivos deste estudo, priorizou-se a produção discente na área da violência doméstica, compreendida entre 1990 e 2006, de um conjunto de programas de pós-graduação em Serviço Social, Psicologia e Saúde Pública localizados na cidade do Rio de Janeiro.

Tal estratégia permitiu explorar - ainda que de forma não exaustiva e consideradas as limitações metodológicas supracitadas - tendências, avanços e lacunas no que diz respeito à violência doméstica. Observando-se a extensão do período analisado (17 anos) e o número total de dissertações e teses produzidas nos programas estudados (3.599), há que se registrar a ainda relativamente reduzida produção na área da violência doméstica (69, ou $2 \%$ do total).

$\mathrm{O}$ estudo permitiu identificar que o tema da violência doméstica contra criança e adolescente é o que tem recebido maior atenção dos mestrandos e doutorandos, seguido do tema da violência contra a mulher. Quanto ao tema da violência contra o idoso no âmbito doméstico, esse ainda apresenta pouca visibilidade em termos de interesse de estudo, porquanto se identificou apenas uma produção.

Levando em consideração que os estudos voltados para a área da violência doméstica ganharam maior visibilidade no Brasil a partir dos anos de 1980, quando se inicia o movimento de democratização no país e se desperta para a defesa e garantia dos direitos de grupos considerados mais vulneráveis, em especial os de crianças e adolescentes e mulheres, os resultados do mapeamento espelham esse interesse, ao revelar que a proporção maior de pesquisas focaliza esses grupos, por vezes de forma conjunta. Os programas da área da saúde figuram como aqueles cuja produção concentra-se mais acentuadamente nestes dois grupos.

No caso dos idosos, a subnotificação parece ser um dos fatores que torna mais difícil o acesso a dados, aspecto este que, associado à recente representatividade demográfica deste grupo etário, deve ser considerado quando da tentativa de compreensão da baixa prevalência de estudos na área. 
Trata-se de constatação desta pesquisa, ratificada por outros estudiosos. (KRUG, 2002; MINAYO; SOUZA, 2003; PAIXÃO JR.; REICHENHEIM, 2006).

No que se refere às temáticas, a análise dos resumos das dissertações e teses permitiu observar avanços nos estudos voltados para delimitar perfis de vítimas e agressores, apontar a importância da capacitação de profissionais e avaliar políticas e programas de proteção. Tal constatação denota um processo de superação da fase inicial de caracterização sociodemográfica e de definição conceitual do fenômeno, vislumbrando o estudo da dinâmica da violência e suas conseqüências. Por outro lado, revelou, também, a falta de estudos sobre violência doméstica cometida contra portadores de distúrbios mentais, portadores de deficiências e homossexuais do sexo masculino e feminino de diversos segmentos etários, aspectos que podem contribuir para maior vulnerabilidade dos grupos estudados.

A reduzida produção de estudos sobre idosos é um dado que valeria ser confrontado com as produções em outros municípios e unidades da federação, bem como indica a necessidade de intensificação de pesquisas sobre este segmento etário.

Igualmente merecem atenção da comunidade acadêmica as especificidades concernentes ao abuso psicológico e à negligência, tipos de violência cujos estudos, embora em crescimento, ainda são reduzidos.

Espera-se que a análise decorrente deste estudo exploratório possa auxiliar no aprimoramento da compreensão acerca da violência doméstica praticada contra grupos especialmente vulneráveis, contribuindo para o desenvolvimento de futuras produções na área.

\section{Referências}

ASSIS, S. G.; CONSTANTINO, P. Violência contra crianças e adolescentes: o grande investimento da comunidade acadêmica na década de 90. In: MINAYO, M. C. S.; SOUZA, E.R. (Org.). Violência sob o olhar da saúde: a infrapolítica da contemporaneidade. Rio de Janeiro: Editora Fiocruz, 2003.p. 163-198.

AZEVEDO, M. A.; GUERRA, V. N. A. (Org.). Crianças vitimizadas: a síndrome do pequeno poder. São Paulo: Iglu, 1989.

BRASIL. Estatuto da Criança e do Adolescente, Lei Federal n. 8.069/90, de 13 de julho de 1990, dispõe sobre a proteção integral à criança e ao adolescente. Brasília: Ministério da Justiça, 1995.

. Estatuto do Idoso, Lei Federal n.10.741, de 01 de outubro de 2003, dispõe sobre o Estatuto do Idoso e dá outras providências. Brasília: Ministério da Justiça, 2003.
Lei Maria da Penha, Lei Federal n. 11.340, de 07 de agosto de 2006, dispõe sobre a criação de mecanismos para coibir a violência doméstica e familiar contra a mulher e dá outras providências. Brasília: Ministério da Justiça, 2007.

Lei n. 8.842, de 4 de janeiro de 1994. Dispõe sobre a política nacional do idoso, cria o Conselho Nacional do Idoso e dá outras providências. Disponível em: <http://www.soleis.com.br/L8842.htm>. Acesso em: 25 jan. 2008.

FURNISS, T. Abuso sexual da criança: uma abordagem multidisciplinar - manejo, terapia e intervenção legal integrados. Porto Alegre: Artes Médicas, 1993.

GUERRA, V. N. A. Violência de pais contra filhos: procuram-se vítimas. São Paulo: Cortez, 1985.

KAMEYAMA, N. A. Trajetória da produção de conhecimento em Serviço Social: avanços e tendências (1975-1997). Cadernos ABESS, São Paulo: Cortez, n. 8, p. 33-76, 1998.

KOWARICK, L. Investigação urbana e sociedade. In: REIS, E.; ALMEIDA, M. H.; FRY, P. (Org.). Pluralismo, Espaço Social e Pesquisa. São Paulo: Hucitec/Anpocs, 1995. p. 45-57.

KRUG, E. G. et al. Relatório mundial sobre violência e saúde. Genebra, Organização Mundial de Saúde, 2002.

MINAYO, M. C. S.; SOUZA, E. R. As múltiplas mensagens da violência contra idosos. In: (Org.) Violência sob o olhar da saúde: a infrapolítica da contemporaneidade. Rio de Janeiro: Editora Fiocruz, 2003. p. 223242.

OLIVEIRA, A. C.; FERNANDES, N. C. B. B. Curso de notificação de maus-tratos contra crianças e adolescentes - lançamento municipal do Programa Estadual Unificado de Aviso por Maus-Tratos (Apomt). In: (Org.). Violências contra crianças e adolescentes: redes de proteção e responsabilização. Rio de Janeiro: Nova Pesquisa, 2007, p. 73-179. (v. 2).

ONU. World Report on Violence against Children. Genebra: Organização das Nações Unidas, 2006.

PAIXÃO JR. C. M.; REICHENHEIM, M. E. Uma revisão sobre instrumentos de rastreamento de violência doméstica contra o idoso. Cadernos de Saúde Pública, Rio de Janeiro, n. 22, v. 6, p. 1137-1149, jun. 2006.

SOARES, B. M. Mulheres invisiveis: violência conjugal e as novas políticas de segurança, Rio de Janeiro: Civilização Brasileira, 1999. 
UNB. Tribuna do Brasil. Agressão deve ser denunciada. Disponível em: $<$ http://www.unb.br/fd/noticiast32.htm $>$. Acesso em: 20 mar. 2008.

\section{Notas}

1 Pesquisa coordenada pela Professora Doutora Sueli Bulhões da Silva, vinculada à linha de pesquisa Violência, Família e Direitos Sociais, do Programa de Pós-Graduação do Departamento de Serviço Social da PUC-Rio, tendo como bolsista PIBIC a aluna Soraia da Silva Rondão.

2 As dissertações e teses que abordam a violência, em geral, tratam de temas tais como: violência estrutural, violência cultural, tráfico de drogas, violência institucional, violência na mídia, homicídios, violência auto-infligida, criminalidade urbana, homofobia etc.

\section{Sueli Bulhões da Silva}

Doutora em Serviço Social pela Universidade Católica de Washington

Professora do Departamento de Serviço Social da Pontifícia Universidade Católica (PUC-Rio)

\section{Antonio Carlos de Oliveira}

Doutorando em Serviço Social pela PUC-Rio

Professor do Departamento de Serviço Social da PUC-Rio

Orientadora: Sueli Bulhões da Silva

\section{PUC-Rio}

Rua Marquês de São Vicente, 225

Vila dos Diretórios, Casa 209 - Gávea

Rio de Janeiro - RJ

CEP: 22451-900 